\title{
Comparison between Landsat 7 Enhanced Thematic Mapper Plus (ETM+) and Landsat 8 Operational Land Imager (OLI) Assessment of Vegetation Indices
}

\author{
Makinde, E.O. ${ }^{1, *}$ and Obigha, A.D. ${ }^{1}$ \\ ${ }^{1}$ Department of Surveying and Geoinformatics, University of Lagos, Lagos, Nigeria \\ Corresponding Author: *estherdanisi@gmail.com; eomakinde@unilag.edu.ng
}

\begin{abstract}
The Landsat system has contributed significantly to the understanding of the Earth observation for over forty years. Since May 2013, data from Landsat 8 has been available online for download, with substantial differences from its predecessors, having an extended number of spectral bands and narrower bandwidths. The objectives of this research were majorly to carry out a cross comparison analysis between vegetation indices derived from Landsat 7 Enhanced Thematic Mapper Plus $($ ETM+) and Landsat 8 Operational Land Imager (OLI) and also performed statistical analysis on the results derived from the vegetation indices. Also, this research carried out a change detection on four land cover classes present within the study area, as well as projected the land cover for year 2030. The methods applied in this research include, carrying out image classification on the Landsat imageries acquired between 1984 - 2016 to ascertain the changes in the land cover types, calculated the mean values of differenced vegetation indices derived from the four land covers between Landsat 7 ETM+ and Landsat 8 OLI. Statistical analysis involving regression and correlation analysis were also carried out on the vegetation indices derived between the two sensors, as well as scatter plot diagrams with linear regression equation and coefficients of determination $\left(R^{2}\right)$. The results showed no noticeable differences between Landsat 7 and Landsat 8 sensors, which demonstrates high similarities. This was observed because Global Environmental Monitoring Index (GEMI), Improved Modified Triangular Vegetation Index 2 (MTVI2), Normalized Burn Ratio (NBR), Normalized Difference Vegetation Index (NDVI), Modified Normalized Difference Water Index (MNDWI), Leaf Area Index (LAI) and Land Surface Water Index (LSWI) had smaller standard deviations. However, Renormalized Difference Vegetation Index (RDVI), Anthocyanin Reflectance Index 1 (ARII) and Anthocyanin Reflectance Index 2 (ARI2) performed relatively poorly because their standard deviations were high. the correlation analysis of the vegetation indices that both sensors had a very high linear correlation coefficient with $R^{2}$ greater than 0.99. It was concluded from this research that Landsat 7 ETM+ and Landsat 8 OLI can be used as complimentary data.
\end{abstract}

Keywords: Landsat 7, Landsat 8, Vegetation Indices, Normalized Difference Vegetation Index (NDVI), Land Cover Change

\subsection{Introduction}

Vegetation Indices (Vis) are mathematical transformations, usually ratios or linear combinations of reflectance measurements in different spectral bands, especially the visible and near-infrared bands. They are widely used in remote sensing practice to obtain information about surface characteristics from multi-spectral measurements, taking advantage of differences in the reflectance patterns between green vegetation and other surfaces (Payero et al., 2004).

Researchers have proposed a number of spectral vegetation indices premised on the contrasts in spectral reflectance between green vegetation and background materials (Rouse et al., 1974; Richardson et al., 1977; Tucker, C.J., 1979; Jackson, R. D., 1983; Omodanisi and Salami, 2014). Of the indices, Normalized Difference Vegetation Index (NDVI) (Rouse et al., 1974) is the most commonly utilized which is based on infrared and red reflectances. NDVI has been used for fuel mapping, foliar moisture stress detection, burn severity mapping, vegetation classification, forest type mapping, invasive weed detection, and land degradation model. The usual form of a vegetation index is a ratio of reflectance 
measured in two bands, or their algebraic combination. Spectral ranges (bands) to be used in Vegetation Indices calculation are selected depending on the spectral properties of plants.

The first Landsat satellite was launched in 1972 with two earth viewing imagers - a return beam vidicon and an 80-meter multispectral scanner (MSS). Landsat 2 and 3, launched in 1975 and 1978 respectively, were configured similarly. In 1984, Landsat 4 was launched with the MSS and a new instrument called the Thematic Mapper (TM). Landsat 5, a duplicate of 4, was launched in 1984 and is still returning useful data. Landsat 6 , equipped with a 15 -meter panchromatic band, was lost immediately after launch in 1993 (U.S. Geological Survey, 2016). Landsat 7 was launched in April, 1999, while Landsat 8 was launched in February 2013 (U.S. Geological Survey, 2016). Table 1 shows the band properties between Landsat 7 ETM+ and Landsat 8 OLI

Table 1: Band properties for Landsat 7 ETM+ and Landsat 8 OLI (U.S.G.S, 2015)

\begin{tabular}{lcc|lcc}
\hline & \multicolumn{2}{c}{ Landsat 7 } & \multicolumn{3}{c}{ Landsat 8 } \\
\hline Band Name & Wavelength $(\mu \mathrm{m})$ & Resolution $(\mathrm{m})$ & Band Name & Wavelength $(\mu \mathrm{m})$ & Resolution $(\mathrm{m})$ \\
\hline & & & Band 1 - Coastal & $0.43-0.45$ & 30 \\
Band 1 -Blue & $0.45-0.52$ & 30 & Band 2 - Blue & $0.45-0.51$ & 30 \\
Band 2 - Green & $0.52-0.60$ & 30 & Band 3 - Green & $0.53-0.59$ & 30 \\
Band 3 - Red & $0.63-0.69$ & 30 & Band 4 - Red & $0.64-0.67$ & 30 \\
Band 4 - NIR & $0.77-0.90$ & 30 & Band 5 - NIR & $0.85-0.88$ & 30 \\
Band 5 - SWIR 1 & $1.55-1.75$ & 30 & Band 6 - SWIR 1 & $1.57-1.65$ & 30 \\
Band 7 - SWIR 2 & $2.09-2.35$ & 30 & Band 7 - SWIR 2 & $2.11-2.29$ & 30 \\
Band 8 - PAN & $0.52-0.90$ & 15 & Band 8 - PAN & $0.50-0.68$ & 15 \\
& & & Band 9 - Cirrus & $1.36-1.38$ & 30 \\
Band 6 - TIR & $10.40-12.50$ & $60 * 30$ & Band 10 - TIRS 1 & $10.6-11.19$ & $100 * * 30$ \\
& & & Band 11 - TIRS 2 & $11.5-12.51$ & $100 * 30$ \\
\hline
\end{tabular}

* ETM+ Band 6 is acquired at 60-meter resolution. Products processed after February 25, 2010are resampled to 30-meter pixels (USGS, 2015).

** TIRS bands are acquired at 100-meter resolution, but are resampled to 30 meters in delivered data product (U.S.G.S, 2015).

The Landsat family satellites have contributed significantly to the understanding of the Earth observation for over forty years. As the application of multi-sensored data is growing importantly and effectively in this era of global environment changes ( $\mathrm{Li}$ et al., 2014), comparison research on the differences between multiple sensors could confirm whether those data are highly related or not; therefore, contributing to the use of various sensors. This is especially helpful particularly in the case of the Landsat system when Landsat 5 was officially retired in January 2013 (Holm, 2013) and Landsat 7 has experienced the scan line corrector failure since 2003 with an estimated 22 percent of data missing per scene (U.S. Geological Survey, 2014).

To be able to carry out effective multi-sensor data analysis, there is a need to compare the results derived from these sensors. Recent literatures have carried out comparison between multiple Landsat sensors to determine if they can be used as complimentary data.

The aim of this study was to carry out a comparison of Vegetation Indices derived from Landsat 7 ETM+ and Landsat 8 OLI Sensors using the Kosofe Local Government Area in Lagos State as a case study. Four sample plots covering four major land cover classes of Built Up area, Heavy Forest, Light forest and Water body, were used to compare the differences and correlation between vegetation indices derived from Landsat 7 ETM+ and Landsat 8 OLI.

\subsection{Materials and Methods}

\subsection{Study Area}

The study area for this research study is the Kosofe Local Government Area (LGA) of Lagos state. Kosofe LGA is located on the north part of Lagos State within latitudes $6^{\circ} 32^{\prime} \mathrm{N}$ and $6^{\circ} 38^{\prime} \mathrm{N}$ and longitudes $3^{\circ} 22^{\prime} \mathrm{E}$ and $3^{\circ} 28^{\prime} \mathrm{E}$, with a land mass of about $81 \mathrm{sq} . \mathrm{km}$. It is bounded on the north by Ogun State, on the west by Ikeja LGA, on the southwest by Shomolu LGA, on the southeast by the Lagos 
Lagoon and on the east by Ikorodu LGA. Kosofe has a tropical wet and dry climate that borders on a tropical monsoon climate.

The vegetation of Kosofe is the swamp forest which had been encroached by construction of houses, markets and other infrastructures. The area has a reasonable amount of built up with vegetation covers around Owode area. The mangroves behind the Ketu area are gradually being encroached on due to construction purposes. The major river in Kosofe LGA is the Ogun River which links to Ogun state. Nigerian Population Commission (2006) puts the population of Kosofe at 682,772 people with 358,935 males and 323,887 females.

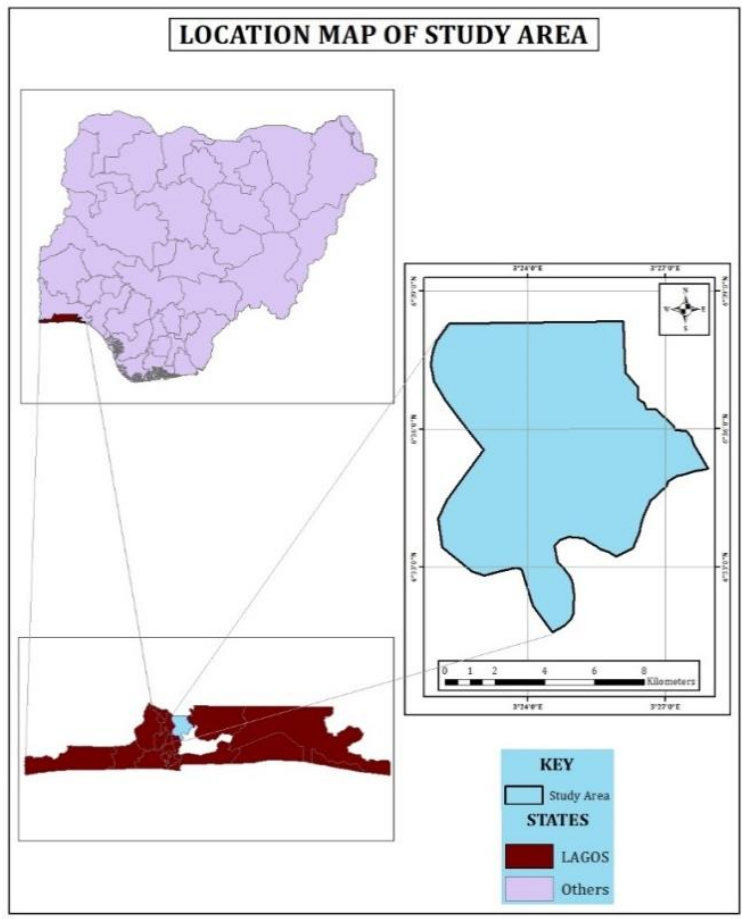

Figure 1: Map of Lagos showing location of Kosofe Local Government

\subsection{Data}

The various data types used for this research and their respective sources are given in the Table 2 below.

Table 2: Data Used and Sources

\begin{tabular}{llcc}
\hline Data & Source & Resolution & Year \\
\hline Landsat 5 TM Imagery & United States Geological Surveys (USGS) & $30 \mathrm{~m}$ & 1984 \\
\hline Landsat 7 ETM+ Imagery & United States Geological Surveys (USGS) & $30 \mathrm{~m}$ & 2000 \\
\hline Landsat 7 ETM+ Imagery & United States Geological Surveys (USGS) & $30 \mathrm{~m}$ & 2006 \\
\hline Landsat 7 ETM+ Imagery & United States Geological Surveys (USGS) & $30 \mathrm{~m}$ & 2015 \\
\hline Landsat 8 OLI Imagery & United States Geological Surveys (USGS) & $30 \mathrm{~m}$ & 2015 \\
\hline Sentinel 2A Imagery & European Space Agency & $10 \mathrm{~m}$ & 2016 \\
\hline Administrative Map of Lagos & Other sources & & 2015
\end{tabular}

\subsection{Methodology}

\subsubsection{Image Preprocessing}

Landsat imageries already come geometrically corrected, but for this study each Landsat imagery had to undergo atmospheric correction to convert the digital number values (DN) to surface reflectance values, necessary for calculating vegetation indices. This correction was done using the Radiometric Correction tool in ENVI 5.0 software. In the Radiometric Calibration tab, the Calibration Type was set to Reflectance. 


\subsubsection{Image Classification}

All bands of each imageries of 1984, 2000, 2006, 2015 and 2016 were layer stacked and colour composites were created to aid image enhancement. The study area of Kosofe LGA was used to clip out each image using the subset tool in ERDAS Imagine environment. Based on the prior knowledge of the study area and a brief reconnaissance survey with additional information from previous research in the study area, a classification scheme was developed for the study area after (Anderson et al., 1976). The four land cover types used are shown in Table 3.

Table 3: Land cover classification scheme

\begin{tabular}{cl}
\hline Code & Land Cover Categories \\
\hline 1 & Built-Up \\
2 & Low Forest \\
3 & Heavy Forest \\
4 & Water Body \\
\hline
\end{tabular}

The classification scheme given in table 3 is a modification of Anderson Classification Scheme of 1976. Urban Area or Built-Up Land is comprised of areas of intensive use with much of the land covered by structure. Included in this category are cities, towns, villages, strip developments along highways, transportation, power, and communication facilities. Low Forest may be broadly defined as land used primarily for production of food and fiber. High Forests have a tree-crown areal density (crown closure percentage) of 10 percent or more, are stocked with tree capable of producing timber or wood products. Water body includes all areas within that persistently are water covered, provided that, if linear, they are at least $1 / 8$ mile $(200 \mathrm{~m})$ wide and, if extended, cover at least 40 acres (16 hectares) (Anderson $e t$ al., 1976).

Maximum Likelihood Classification was carried out for all images of 1984, 2000, 2006, 2015 and 2016 using the four land cover classes.

\subsubsection{Accuracy Assessment of Classification}

Accuracy assessment of the classification was determined by means of a confusion matrix (sometimes called error matrix), which compares, on a class-by-class basis, the relationship between reference data (ground truth) and the corresponding results of a classification. Such matrices are square, with the number of rows and columns equal to the number of classes, in this case, 4 . The error matrix, producer's accuracy, user's accuracy, overall accuracy and kappa accuracy was computed for each year.

\subsubsection{Cross Comparative Analysis of Vegetation Indices}

Ten vegetation indices were carried out on Landsat 7 and Landsat 8 imageries of 2015. These vegetation indices majorly covered between the Red, Near Infrared (NIR) and Shortwave Infrared (SWIR) bands. The corresponding formulas for these indices are given below:

i. Anthocyanin Reflectance Index 1 (ARI1) $=\frac{1}{\text { R550 }}-\frac{1}{\text { R700 }}$

ii. Anthocyanin Reflectance Index $2\left(\right.$ ARI2) $=$ R800 $\left[\frac{1}{R 550}-\frac{1}{R 700}\right]$

iii. Global Environmental Monitoring Index $(\mathrm{GEMI})=\eta(1-0.25 *$ eta $)-\frac{\text { RED }-0.125}{1-\mathrm{RED}}$

$$
\eta=\frac{2\left(\mathrm{NIR}^{2}-\mathrm{RED}^{2}\right)+1.5 * \mathrm{NIR}+0.5 * \mathrm{RED}}{\mathrm{NIR}+\mathrm{RED}+0.5}
$$

iv. Improved Modified Traigular Vegetation Index 2

$$
(\text { MVTVI2 })=\frac{1.5 *[1.2 *(\text { NIR }- \text { GREEN })-2.5 *(\text { RED }- \text { GREEN })]}{\sqrt{(2 * \text { NIR }+1)^{2}-(6 * \text { NIR }-5 * \sqrt{\text { RED })-0.5}}}
$$

v. Leaf Area Index $(\mathrm{LAI})=(3.618 * \mathrm{EVI}-0.118)$

$$
\mathrm{EVI}=2.5 * \frac{(\mathrm{NIR}-\mathrm{RED})}{(\mathrm{NIR}+6 * \mathrm{RED}-7.5 * \mathrm{BLUE}+1)}
$$


vi. $\quad$ Land Surface Water Index $(\mathrm{LSWI})=\frac{\text { NIR-SWIR1 }}{\text { NIR+SWIR1 }}$

vii. Normalized Burn Ratio (NBR) $=\frac{\text { NIR-SWIR2 }}{\text { NIR+SWIR2 }}$

viii. Normalized Difference Vegetation Index $(N D V I)=\frac{N I R-R E D}{N I R+R E D}$

ix. Normalized Difference Water Index $(N D W I)=\frac{\text { NIR-SWIR }}{\text { NIR+SWIR }}$

X. Renormalized Difference Vegetation Index (RDVI) $=\frac{\text { NIR-RED }}{\sqrt{\mathrm{NIR}+\mathrm{RED}}}$

\subsubsection{Statistical Analysis}

Statistical analysis methods are widely used in cross-comparison between various satellite sensors. Statistical analysis mainly consists of two parts in this study. Firstly, the average values of differenced vegetation indices for six polygons to demonstrate the similarity or difference between Landsat-7 ETM+ and Landsat-8 OLI sensor were cross-compared. Secondly, scatter plots of vegetation indices for cross-comparisons were applied to calculate the coefficients of determination $\left(\mathrm{R}^{2}\right)$ based on linear correlation analysis. Also, the linear regression equation was also computed and displayed on each sample plot.

\subsubsection{Change Prediction for 2030}

Change prediction was carried out on the study area for the year 2030. The year 2030 was chosen due to the time difference between acquired images. This was necessary to have a view of the land cover of the study area in the future. Change prediction was carried out using the Idrisi Selva software, which uses a transition matrix from two consecutive years of land cover classification to calculate the probability of the land cover change in the future

\subsection{Results and Discussion}

\subsection{Land Cover Change Detection}

Table 4 shows the results of the areal cover for the landcover types for each year under study. It presents the area covered by each land cover class for each year under study as well as the percentage cover.

Table 4: Land Cover Distribution of Study Area

\begin{tabular}{|c|c|c|c|c|c|c|c|c|c|c|}
\hline \multicolumn{11}{|c|}{ Land Cover Analysis } \\
\hline & \multicolumn{2}{|c|}{1984} & \multicolumn{2}{|c|}{2000} & \multicolumn{2}{|c|}{2006} & \multicolumn{2}{|c|}{2015} & \multicolumn{2}{|c|}{2016} \\
\hline & $\begin{array}{c}\text { Area } \\
(\mathrm{Sq} . \mathbf{K m})\end{array}$ & $\begin{array}{c}\text { Area } \\
(\%)\end{array}$ & $\begin{array}{c}\text { Area } \\
(\mathrm{Sq} . \mathrm{Km})\end{array}$ & $\begin{array}{c}\text { Area } \\
(\%)\end{array}$ & $\begin{array}{c}\text { Area } \\
(\mathrm{Sq} . \mathrm{Km}) \\
\end{array}$ & $\begin{array}{c}\text { Area } \\
(\%)\end{array}$ & $\begin{array}{c}\text { Area } \\
(\mathrm{Sq} . \mathrm{Km})\end{array}$ & $\begin{array}{c}\text { Area } \\
(\%)\end{array}$ & $\begin{array}{c}\text { Area } \\
(\mathrm{Sq} . \mathbf{K m}) \\
\end{array}$ & $\begin{array}{c}\text { Area } \\
(\%)\end{array}$ \\
\hline Water Body & 15.60 & 19.32 & 15.67 & 19.40 & 9.36 & 11.59 & 12.55 & 15.54 & 8.72 & 10.80 \\
\hline Built Up & 15.30 & 18.95 & 33.99 & 42.08 & 30.57 & 37.85 & 36.87 & 45.64 & 41.74 & 51.68 \\
\hline Heavy Forest & 24.46 & 30.29 & 21.69 & 26.85 & 21.51 & 26.63 & 18.06 & 22.36 & 16.53 & 20.47 \\
\hline Light Forest & 25.39 & 31.44 & 9.42 & 11.66 & 19.33 & 23.93 & 13.30 & 16.46 & 13.77 & 17.05 \\
\hline Total & 80.75 & 100.00 & 80.77 & 100.00 & 80.77 & 100.00 & 80.78 & 100.00 & 80.76 & 100.00 \\
\hline
\end{tabular}

From Table 4, built up covered 15.30 sq.km of the total study area, which is about $18.95 \%$ in 1984 . This increased to about $42.08 \%$ with 33.99 sq. $\mathrm{km}$ in 2000 . There was a slight decrease in 2006 with 30.57 sq.km and an increase to 36.87 sq.km and 41.74 sq.km in 2015 and 2016 respectively. Water body covered $19.32 \%$ of the study area with 15.60 sq.km in 1984 . It slightly increased to about $19.40 \%$ in 2000 with 15.67 sq.km. in 2015 and 2016, water body covered 12.55 sq.km and 8.72 sq.km. respectively.

In 1984, heavy forest covered 24.46 sq.km., in 2000 it decreased to about 21.69 sq.km. Heavy forest experienced a decrease with 26.88 sq.km, 18.06 sq.km and 16.53 sq.km. in 2006, 2015 and 2016 respectively. Light forest on the other hand, experienced a fluctuating coverage, covering $31.44 \%$ in 
1984 to $11.66 \%$ in 2000 . It increased to $23.93 \%$ with 19.33 sq.km. in 2006 and decreased to 13.30 sq.km and 13.77 sq.km. in 2015 and 2016 respectively.

\subsubsection{Land Cover Maps}

Figure 2 below shows the classified land cover maps for all years under study. Built up is represented in red colour, heavy forest in dark green, light forest in light green and water body in blue. This colour representation is a modification of (Anderson et al., 1976).
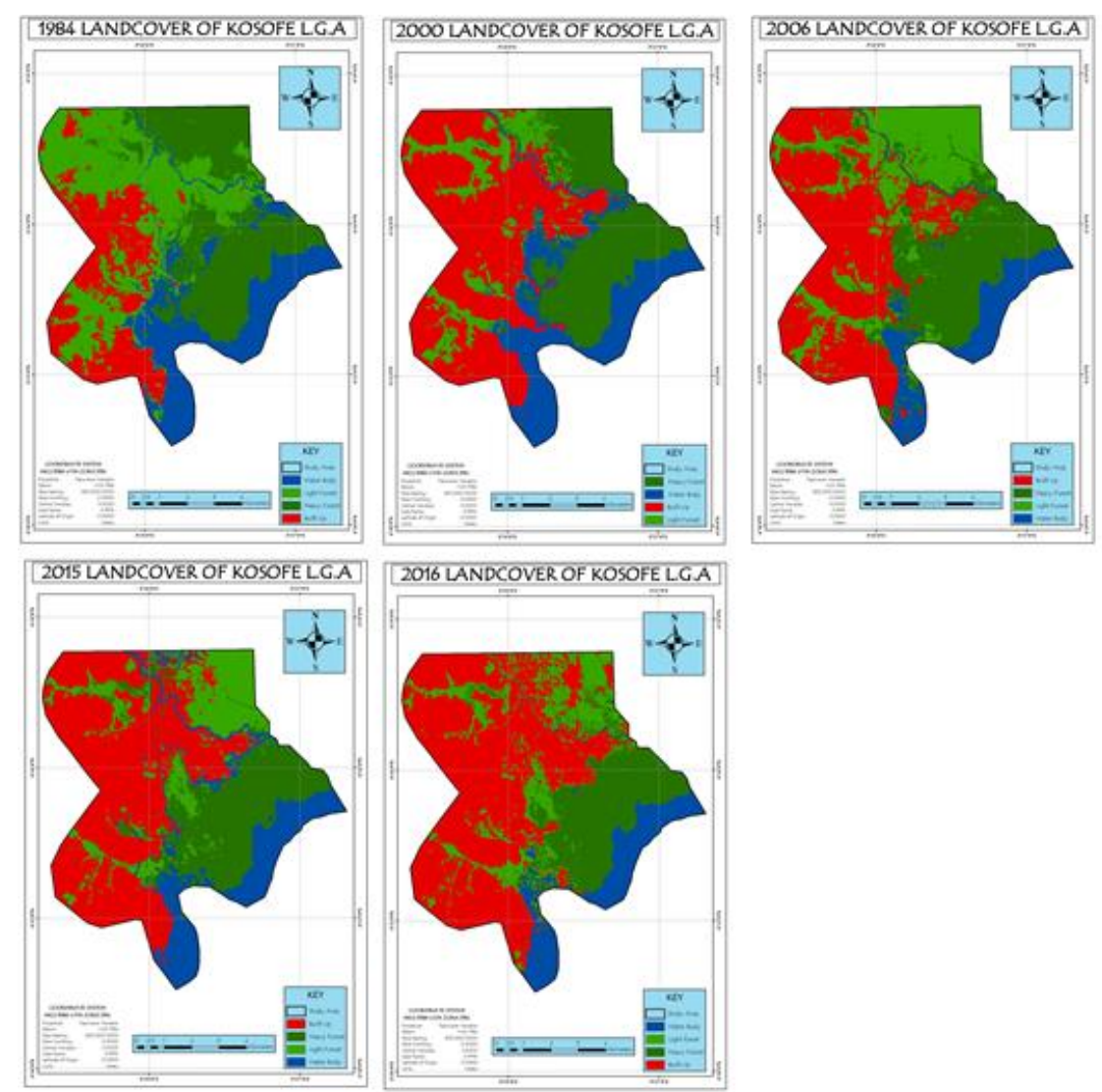

Figure 2: Classified Land Cover Maps

\subsubsection{Accuracy Report}

The accuracy report for 2016 is shown in Table 5.

Table 5: Accuracy Report for 2016

\begin{tabular}{lccccc}
\hline $\begin{array}{c}\text { Classified } \\
\text { Data }\end{array}$ & $\begin{array}{c}\text { Reference } \\
\text { Total }\end{array}$ & $\begin{array}{c}\text { Classified } \\
\text { Totals }\end{array}$ & $\begin{array}{c}\text { Number of } \\
\text { Correct }\end{array}$ & $\begin{array}{c}\text { Producer's Accuracy } \\
(\boldsymbol{\%})\end{array}$ & $\begin{array}{c}\text { User's Accuracy } \\
(\boldsymbol{\%})\end{array}$ \\
\hline Water Body & 100 & 80 & 80 & 80.00 & 100.00 \\
Built Up & 100 & 120 & 100 & 100.00 & 83.33 \\
Heavy Forest & 100 & 100 & 99 & 99.00 & 99.00 \\
Light Forest & 100 & 100 & 99 & 99.00 & 99.00 \\
Total & 400 & 400 & 378 & 94.50 & 95.33 \\
Overall Accuracy $-\mathbf{9 4 . 5 0 \%}$ & & & & \\
Overall Kappa Accuracy - 92.67\% & & & & \\
\hline
\end{tabular}

\subsection{Cross-Comparison between the Values of Vegetation Indices Derived from ETM+ and OLI}

Figure 3 shows the graphs of the mean values of differenced vegetation indices for all four sample plots between Landsat 7 ETM+ and Landsat 8 OLI. Sample plot 1, 2, 3 and 4 represents heavy forest, built up, light forest and water body respectively. From the graph of ARI1, it can be seen that it has a higher 
standard deviation. The mean differences of heavy forest and light forest are more closely fixed compared to mean differences of built up and water body. In ARI2, the mean differences of heavy forest, light forest and built up are more closely clustered compared to that of water body. This also has a high standard deviation.

GEMI has a standard deviation of 0.011 and the mean values of the sample plots are closely related. LAI has a standard deviation of 0.16 , it can be seen that the mean values are scattered around the mean. LSWI, MNDWI, MTVI2, NBR, NDVI and RDVI have standard deviations of 0.041, 0.039, 0.012, $0.030,0.032$ and 0.182 respectively. This shows that the mean differences between Landsat 7 ETM+ and Landsat 8 OLI are not so noticeable. ARI1, ARI2, LAI and RDVI have higher standard deviations which indicates that there were higher differences between Landsat 7 ETM+ and Landsat 8 OLI in these vegetation indices.
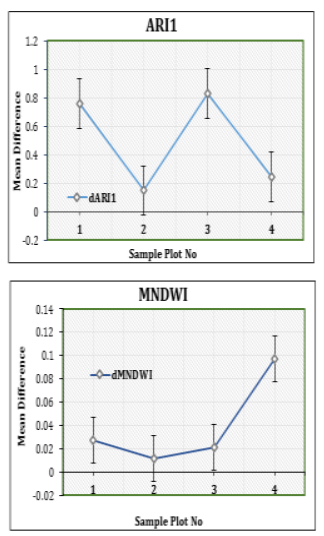
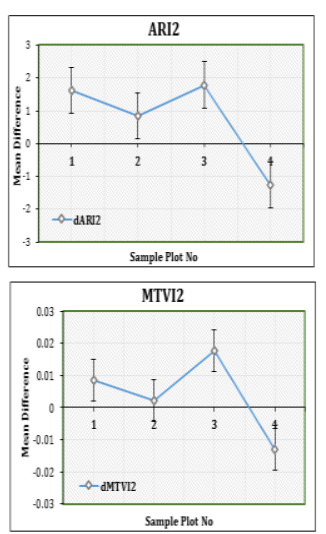
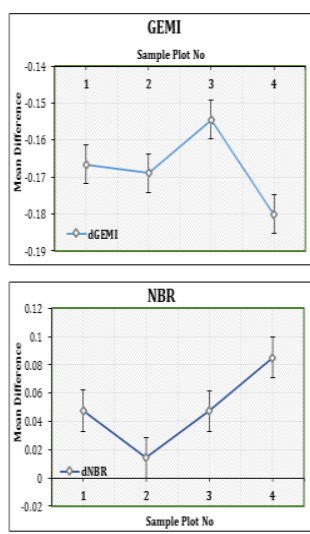
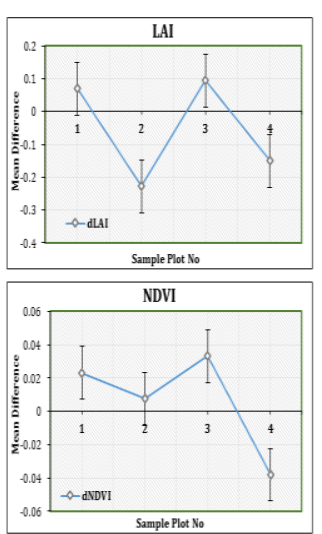
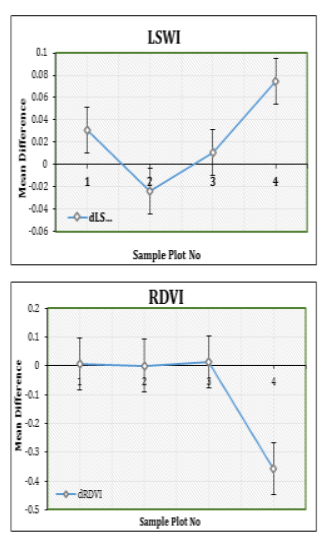

Figure 3: Mean Values of Differenced Vegetation Indices Derived from Landsat-7 ETM+ and Landsat-8 OLI Images within Five Sample Plots

\subsection{Statistical Analysis of Vegetation Indices Derived from ETM+ and OLI}

Figures 4-13, shows the scatter plot diagrams with linear regression equation and coefficients of determination $\left(\mathrm{R}^{2}\right)$ between Landsat 7 ETM+ and Landsat 8 OLI for each vegetation index in all four sample plots. For each diagram, the linear regression equation and the coefficient of determination $\left(\mathrm{R}^{2}\right)$ is given. In each plot, Landsat 8 OLI derived vegetation indices values are displayed on the $\mathrm{X}$-axis while Landsat 7 ETM+ derived vegetation indices values are displayed on the Y-axis.

The diagrams show that the coefficient of determination $\left(\mathrm{R}^{2}\right)$ for all plots were greater than 0.99 . this demonstrates that vegetation indices derived from Landsat 7 ETM+ and Landsat 8 OLI are highly linearly correlated.
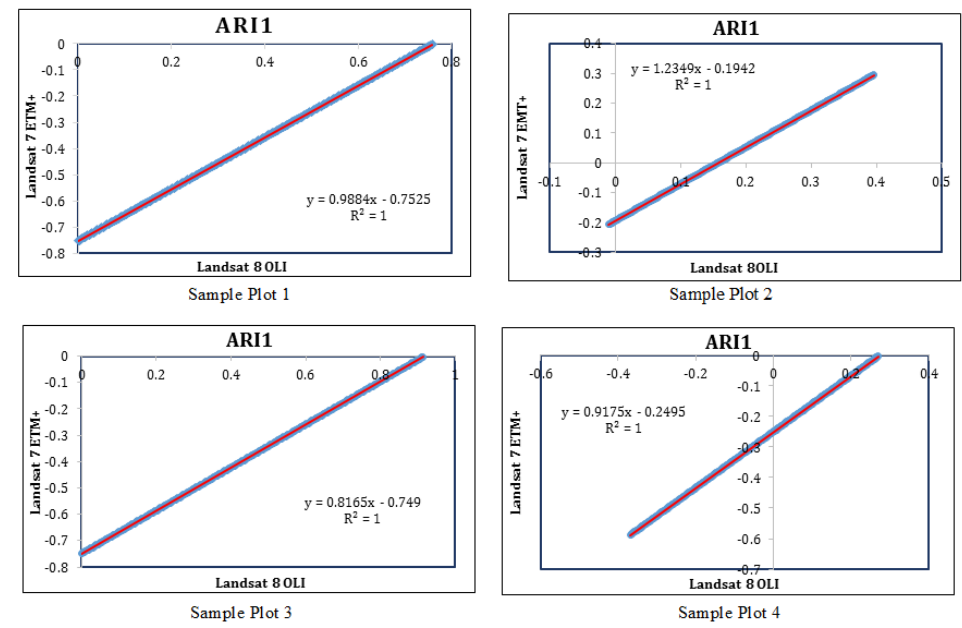

Figure 4: Statistical relationship between Landsat-7 ETM+ and Landsat-8 OLI ARI1 values for the four sample plots 

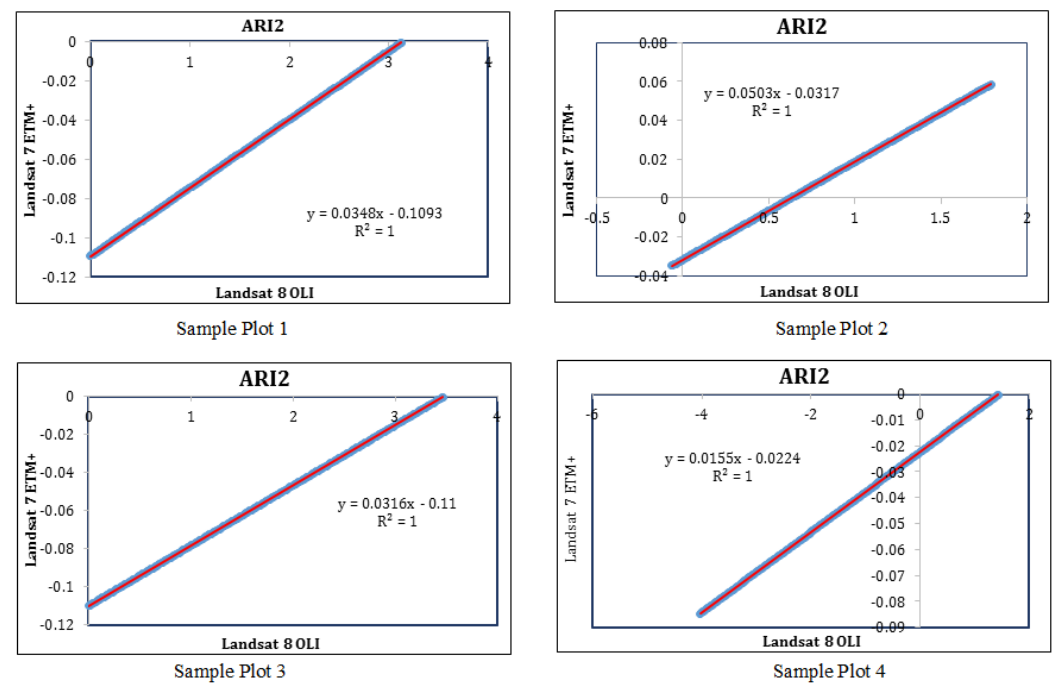

Figure 5: Statistical relationship between Landsat-7 ETM+ and Landsat-8 OLI ARI2 values for the four sample plots
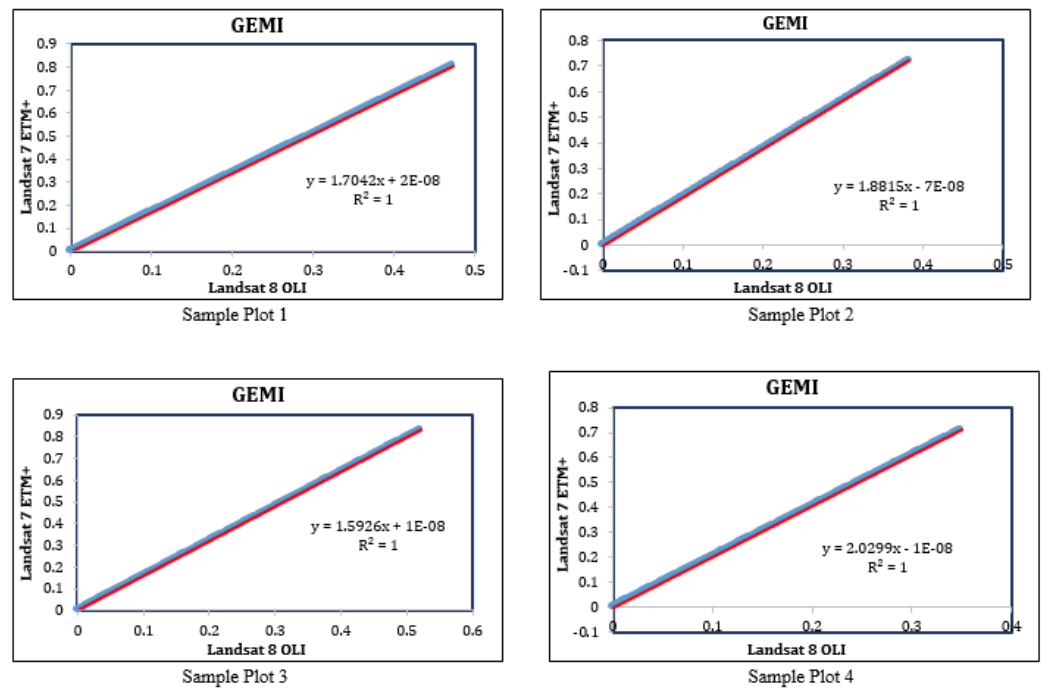

Figure 6: Statistical relationship between Landsat-7 ETM+ and Landsat-8 OLI GEMI values for the four sample plots
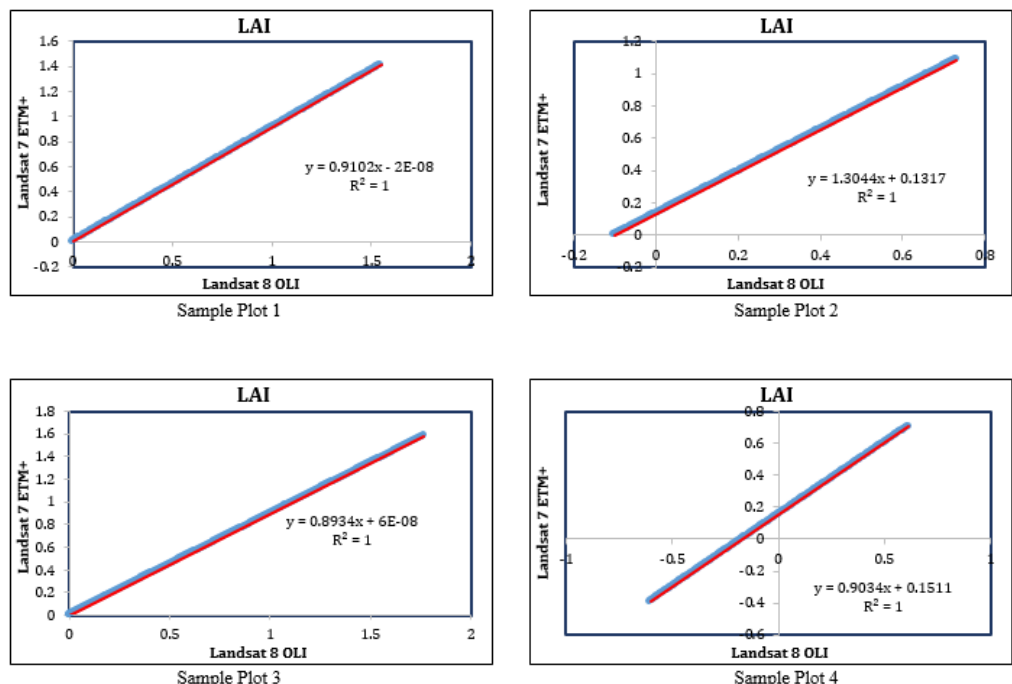

Figure 7: Statistical relationship between Landsat-7 ETM+ and Landsat-8 OLI LAI values for the five sample plots 

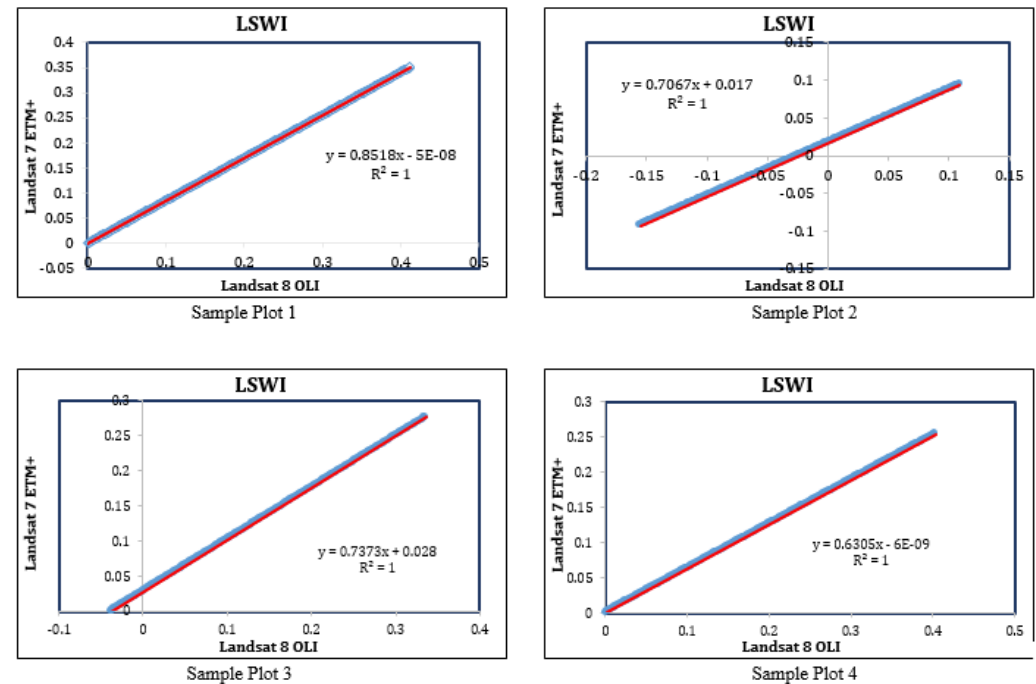

Figure 8: Statistical relationship between Landsat-7 ETM+ and Landsat-8 OLI LSWI values for the four sample plots
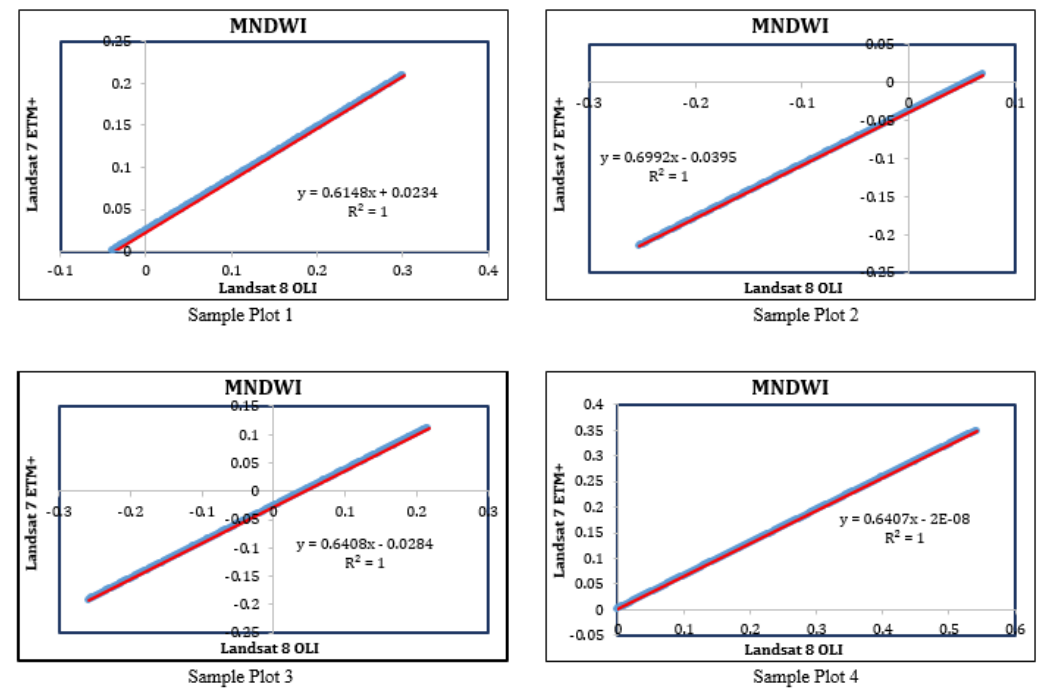

Figure 9: Statistical relationship between Landsat-7 ETM+ and Landsat-8 OLI MNDWI values for the four sample plots
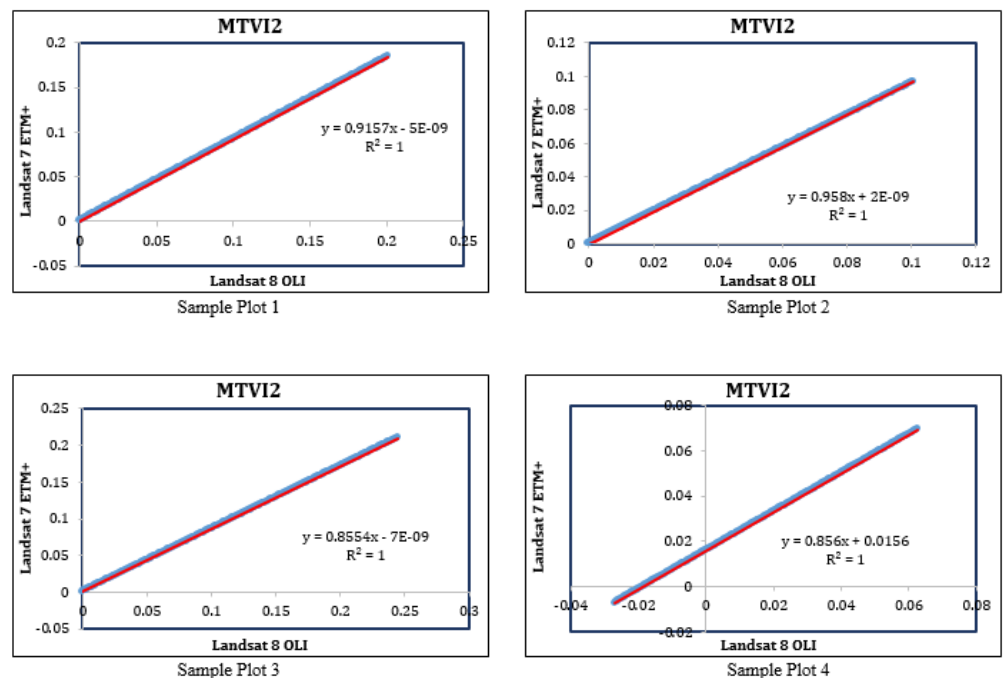

Figure 10: Statistical relationship between Landsat-7 ETM+ and Landsat-8 OLI MTVI2 values for the four sample plots 

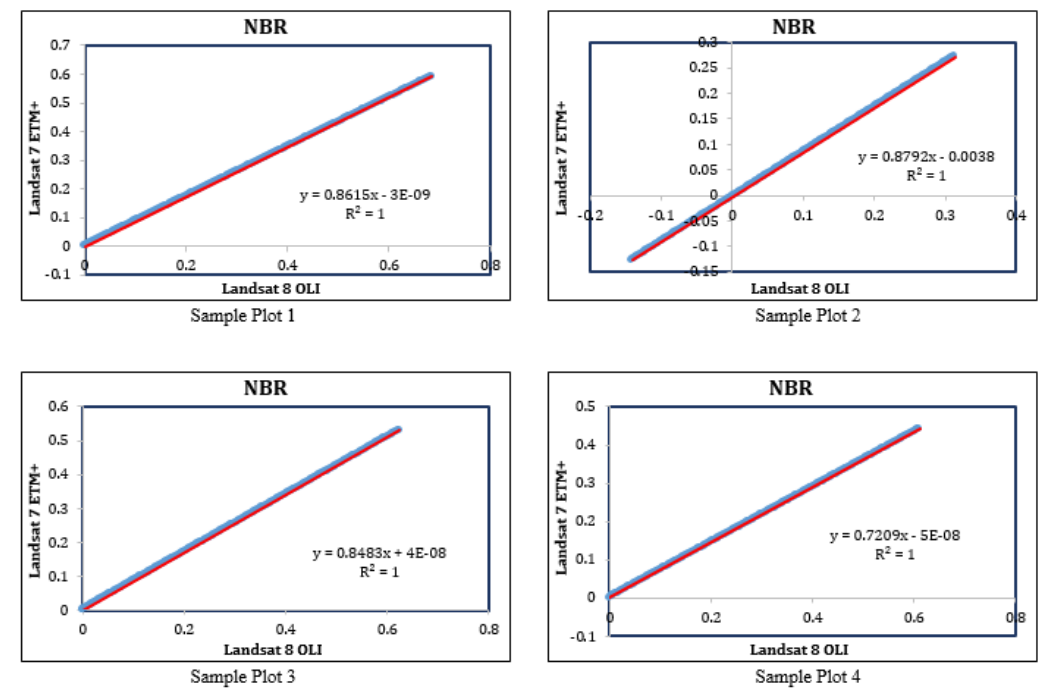

Figure 11: Statistical relationship between Landsat-7 ETM+ and Landsat-8 OLI NBR values for the four sample plots
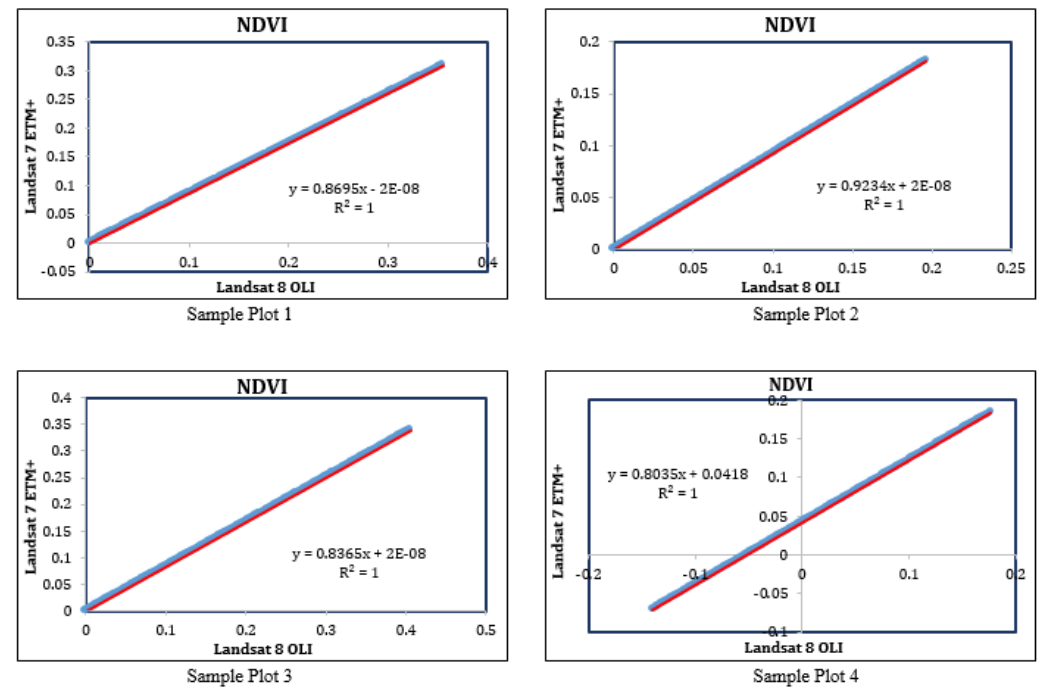

Figure 12: Statistical relationship between Landsat-7 ETM+ and Landsat-8 OLI NDVI values for the four sample plots
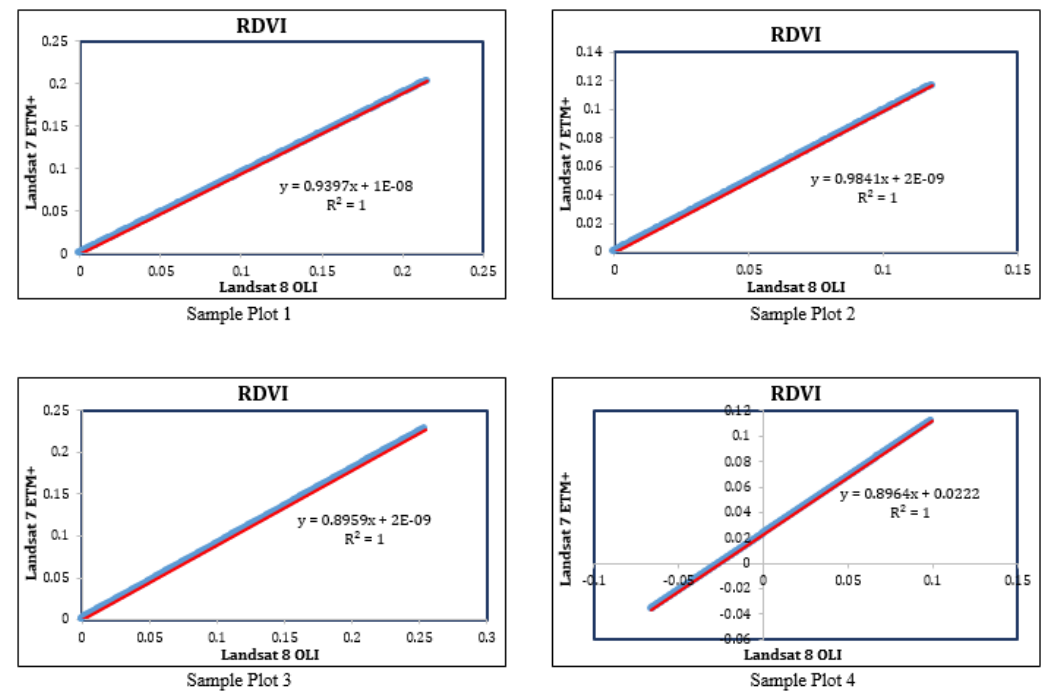

Figure 13: Statistical relationship between Landsat-7 ETM+ and Landsat-8 OLI RDVI values for the four sample plots 


\subsection{Land Cover Projection for 2030}

Table 5 shows the result of the projected areal cover for each land cover class for year 2030. It shows that by the year 2030, Built Up area would have covered about $64.87 \%$ of the study area while other lands cover classes like light forest, heavy forest and water body would reduce.

Table 5: Land Cover Projection for 2030

\begin{tabular}{lcc}
\hline Class & Area (sq. Km.) & Area (\%) \\
\hline Heavy Forest & 11.38 & 14.08 \\
Water Body & 7.46 & 9.24 \\
Built Up & 52.39 & 64.87 \\
Light Forest & 9.56 & 11.83 \\
Total & $\mathbf{8 0 . 7 7}$ & $\mathbf{1 0 0}$ \\
\hline
\end{tabular}

\subsection{Discussion}

In this study, Landsat imagery (Landsat 7 and Landsat 8) of 2015 covering the Kosofe LGA were used. The comparison was carried out in two parts; comparison of the mean differences between the vegetation indices derived from Landsat 7 and Landsat 8 and statistical analysis involving regression and correlation analysis. Four sample plots covering four land cover types of built up, heavy forest, light forest and water body were used for the comparison.

In comparing the mean differences of vegetation indices derived for each plot, it was observed that there existed subtle differences between Landsat 7 and Landsat 8 sensors, which demonstrates high similarities. This finding agrees with (Peng et al., 2014) and (Nguyen \& Pham, 2014). This was observed because GEMI, MTVI2, NBR, NDVI, MNDWI, LAI and LSWI had smaller standard deviations. NDVI had mean difference value of 0.0069 , GEMI with -0.16 , MTVI2 with 0.0038 , NBR with 0.049 , MNDWI had 0.033, LAI with -0.05 and LSWI with 0.036 . MTVI2 might be the optimum parameter with a mean difference of close to zero, followed by GEMI and NDVI.

However, RDVI, ARI1 and ARI2 performed relatively poorly because their standard deviations were higher and their mean difference values were $-0.084,0.50$ and 0.75 respectively. One very important factor that could have led to the fluctuations of the differenced values of vegetation indices might be the different land cover types among the selected four sample plots.

It was also observed from the correlation analysis of the vegetation indices that both sensors had a very high linear correlation coefficient with $\mathrm{R}^{2}$ greater than 0.99. This also agrees with (Peng et al., 2014) and (Nguyen \& Pham, 2014). The subtle differences and high correlation of vegetation indices demonstrates that Landsat 8 OLI and Landsat 7 ETM+ imagery can be used as complimentary data.

The land change analysis revealed that considerable change had occurred in the study area between 1984 and 2016. Between 1984 and 2016, built up land experienced a 172.81\% increase from 15.30 sq.km in 1984 to 41.74 sq.km in 2016. Heavy forest experienced a $-32.42 \%$ decrease with 24.46 sq.km in 1984 to 16.53 sq.km. in 2016. Light forest also experienced a decrease by $-45.77 \%$ with 25.39 sq.km in 1984 to 13.77 sq.km in 2016. Water body experienced a decrease of $-44.10 \%$ with 15.60 sq.km 1984 to 8.72 sq. $\mathrm{km}$ in 2016 . These decrease in vegetation land cover types is mostly associated to human developments which has led to a high rate of deforestation. Built up area increased drastically during the period under study due to the same urbanization and economic factors.

It is projected that built up land will have an increase of $25.52 \%$ from 41.74 sq.km in 2016 to 52.39 sq.km in 2030, covering about 64.87 sq.km of the total study area. However, heavy forest, light forest and water body are projected to experience a decrease of $-31.16 \%,-30.57 \%$ and $-14.45 \%$ respectively in 2030. This is highly due to urbanization and development.

\subsection{Conclusion}

This research study carried out a comparison between vegetation indices derived from Landsat 7 ETM+ and Landsat 8 OLI. It used Landsat images of 2015 covering the Kosofe LGA in Lagos state for this comparison. Comparison between the different vegetation indices derived from both sensors basically 
demonstrated that there are no noticeable differences between the Landsat-7 ETM+ and Labdsat-8 OLI sensors. This was clearly shown by GEMI, MTVI2, NBR, NDVI, MNDWI, LAI, and LSWI, because their standard deviations were closer to zero. However, RDVI, ARI1 and ARI2 performed relatively poorly, because the standard deviations were higher. Also, correlation analysis of the vegetation indices indicated that both sensors had a very linear correlation coefficient, with $\mathrm{R}^{2}$ greater than 0.99 . The subtle differences and high correlation of vegetation indices demonstrated that Landsat-7 ETM+ and Landsat8 OLI imagery can be used as complementary data.

\section{References}

Anderson, J., Hardy, E., Roach, J., \& Witmer, R. (1976). A Land Use and Land Cover Classification System for Use with Remote Sensor Data. U.S. Geological Survey Professional Paper , 28.

Holm, T. (2013). Landsat: Building a Future on 40 Years of Success.

Jackson, R. D. . (1983). Spectral indices in n-space. Remote Sensing Environment, 409-421.

Li, P., Jiang, L., \& Fen, Z. (2014). Cross-Comparison of Vegetation Indices Derived from Landsat-7 Enhanced Thematic Mapper Plus (ETM+) and Landsat-8 Operational Land Imager (OLI) Sensors. Remote Sensing, 6, pp.310-329

Nguyen, T. H., \& Pham, X. (2014). A Comparison of Vegetation Spectral Indices Derived from Landsat 8 and Previous Landsat Generations.

Omodanisi, E.O. and Salami, A.T. (2014) An Assessment of the Spectra Characteristics of Vegetation in South Western Nigeria. IERI Procedia, Elsevier, USA, 9 (2014) 26 - 32.

Payero, J. O., Neale, C., \& Wright, J. (2004). Comparison of Eleven Vegetation Indices for Estimating Plant Height of Alfalfa and Grass. Applied Engineering in Agriculture, 20(3), pp.385-393.

Peng, L., Luguang, J., \& Zhiming, F. (2014). Cross-Comparison of Vegetation Indices Derived from Landsat-7 Enhanced Thematic Mapper Plus (ETM+) and Landsat-8 Operational Land Imager (OLI) Sensors. Journal of Remote Sensing, pp.310-329.

Rouse, J.W., Haas, R.H., Deering, D.W. , \& Sehell, J.A. . (1974). Monitoring the vernal advancement and retrogradation (Green wave effect) of natural vegetation. Texas.

Richardson, A.J. , \& Wiegand, C.L. . (1977). Distinguishing vegetation from soil background information. Photogrammetric Engineering and Remote Sensing, pp.1541-1552.

Tucker, C.J. . (1979). Red and photographic infrared linear combinations for monitoring vegetation. Remote Sensing of Environment, 127-150.

U.S. Geological Survey. (2014). Using Landsat 7 Data.

U.S. Geological Survey. (2015). Landsat.

U.S. Geological Survey. (2016). Landsat 8 Data Users Handbook. 